\section{Crystallised English}

David Crystal, The Cambridge Encyclopedia of the English Language, Cambridge University Press, 1995, pp. vii +489 , hb 0-521-40179, $£ 29.95$. *In 24 sections, grouped into 6 parts, each containing numerous superbly-designed double-page spreads, with many high-quality colour illustrations. Covers: an opening section on Modelling English, then the following six divisions and their many subdivisions (1) The History of English, including its origins, Old English, Middle English, Early Modern English, Modern English, and World English. (2) English Vocabulary, covering the nature and sources of the lexicon, etymology, lexical structure, and lexical dimensions. (3) English Grammar, including grammatical mythology, word structure, word classes, and sentence structure. (4) Spoken and written English, including the sound system and the writing system. (5) Using English, including varieties of discourse and regional, social, and personal variation, each with many component sections. (6) Learning about English, including learning English as a mother tongue (bringing in such matters as child language acquisition, literacy, grammatical development, and language disability) and new ways of studying the language (including corpora, dictionaries, and technological developments). With Appendices: a glossary; special symbols and abbreviations, references, further reading, an index of linguistic items, an index of authors and personalities, an index of topics, and acknowledgements. Crystal's work makes many direct and indirect references to English Today and its contents, as in the specimen below:

\section{WHAT COUNTS AS A WORD?}

The cover of the periodical English Today poses a question of considerable theoretical and practical significance. Usually, people look at the spaces in a piece of writing, and think that they are enough to decide the matter. So, the first sentence of this paragraph, we would all agree, contains 16 words. Unfortunately for lexicologists, word space is not an infallible guide, as the cover examples show. - Hyphens complicate matters: shall we count eat-asmuch-as-you-like as a single word? or Highs-Lows?

- The absence of hyphens complicates matters: is Value for Money truly three separate words?

- Unusual compounds complicate matters: shall we count FLYAWAY and CITYSPRINT as single words?

- Abbreviations complicate matters: are $B A$ and $B C a l$ one word or two?
Several other kinds of difficulty can be given - Meaning complicates matters: bear (the animal) and bear (to carry) are plainly different words, but are lock (on the door) and lock (in a canal) different words? Is high in high tea, high priest, and high season the same word?

- Usage complicates matters: people sometimes write flowerpot, sometimes flower pot, and sometimes flower-pot.

- Idioms complicate matters: if we insist that a word should have a clear meaning, then how many words are there in get my act together and get my own back?

Problems of this kind mean that it is always wise to take word estimates cautiously, especially when evaluating the competing claims about coverage made by English dictionaries. Equally, the problems present an interesting challenge to lexicologists, as they get to grips with their task.

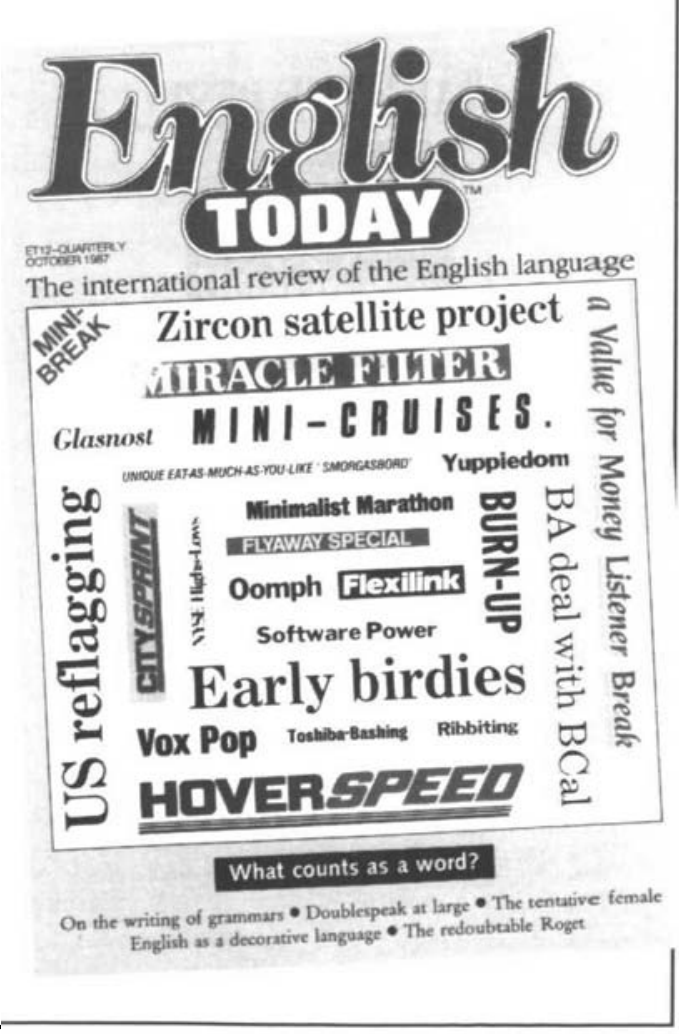

which analyses how language users understand the links between words in a sentence. With selfassessment questions at the end of each section, references, and an index.

Laurie Bauer, Watching English Change: An Introduction to the Study of Linguistic Change in 